\title{
Estrutura do pasto de capim-braquiária com variação de alturas
}

\author{
Manoel Eduardo Rozalino Santos ${ }^{1}$, Dilermando Miranda da Fonseca ${ }^{2}$, Guilherme Portes \\ Silva ${ }^{3}$, Roberson Machado Pimentel ${ }^{4}$, Victor Valério de Carvalho ${ }^{4}$, Simone Pedro da Silva ${ }^{5}$ \\ ${ }^{1}$ Doutorando do Departamento de Zootecnia - Universidade Federal de Viçosa. \\ 2 Departamento de Zootecnia - Universidade Federal de Viçosa. \\ ${ }^{3}$ Graduando em Agronomia - Universidade Federal de Viçosa. \\ ${ }^{4}$ Graduando em Zootecnia - Universidade Federal de Viçosa \\ ${ }^{5}$ Mestranda do Departamento de Zootecnia - Universidade Federal de Viçosa.
}

RESUMO - Este trabalho foi conduzido com o objetivo de avaliar as características estruturais da Brachiaria decumbens cv. Basilisk. Foram avaliadas quatro alturas de plantas (10, 20, 30 e $40 \mathrm{~cm}$ ) dentro de uma mesma pastagem, em um delineamento experimental de blocos casualizados com duas repetições. A variação na altura inicial das plantas no pasto de capim-braquiária apresentou resposta linear e negativa. As massas de lâmina foliar verde, colmo verde, material morto, forragem verde e forragem total aumentaram linearmente com a altura das plantas no pasto. Contrariamente, houve redução linear na relação lâminas foliares verdes/colmos verdes com a altura das plantas no pasto (de 1,16 para 0,58). A altura das plantas no pasto teve efeito mais pronunciado sobre o aumento das massas de colmo verde e material morto que sobre a massa de lâmina foliar verde. A densidade volumétrica de lâminas foliares verdes decresceu (de 97,09 para 39,07 kg/cm.ha de MS) com a altura das plantas no pasto. Mesma resposta ocorreu para as densidades volumétricas de forragem verde (de 181,62 para 107,85 kg/cm.ha de MS) e forragem total (de 283,39 para 195,72 kg/cm.ha de MS). Por outro lado, não houve efeito da altura das plantas no pasto sobre as densidades volumétricas de colmos verdes e material morto, que apresentaram valores médios de 80,95 e 95,61 kg/cm.ha de MS, respectivamente. A altura das plantas no pasto teve efeito quadrático sobre a interceptação de luz pelo dossel. Áreas da pastagem com alturas de 10, 20, 30 e 40 cm apresentaram valores de interceptação luminosa de 56,15; 85,16; 93,39 e $96,57 \%$, respectivamente. Ocorre variação espacial e temporal na estrutura do pasto de $B$. decumbens manejado sob lotação contínua.

Palavras-chave: altura do pasto, Brachiaria decumbens, densidade volumétrica de forragem, interceptação de luz, massa de forragem

\section{Structure of signal grass pasture with height variation}

\begin{abstract}
This study was carried out aiming to evaluate the structural characteristics of Brachiaria decumbens cv. Basilisk pasture. Four heights of plants $(10,20,30$ and $40 \mathrm{~cm})$ were evaluated within the same grazing area in a randomized block experimental design with two repetitions. Variation in the initial height of the signal grass pasture plant showed a linear and a negative response. The masses of green leaf blade mass, live stem, dead material, live forage and total forage linearly increased with heights of the plants on the pasture. However, it was observed a linear reduction in green leaf blade/live stem ratio and the height of the plants on the pasture (from 1.16 to 0.58). Plant height on the pasture had a stronger effect on the increase of live stem and the dead material masses than it had on the green leaf blade mass. Volumetric density of green leaf blade decreased (from 97.09 to $39.07 \mathrm{~kg} / \mathrm{cm}$ ha DM) with plant height on the pasture. The same response was found for volumetric densities of live forage (from 181.62 to $107.85 \mathrm{~kg} / \mathrm{cm}$.ha dry matter) and total forage (from 283.39 to $195.72 \mathrm{~kg} / \mathrm{cm}$.ha dry matter). On the other hand, the plant heights on pasture did not affect volumetric density of live stem and dead material, which showed mean values 80.95 and $95.61 \mathrm{~kg} / \mathrm{cm}$.ha DM, respectively. The heights of the plants on pasture had a quadratic effect on light interception by the canopy. Grazing areas with heights of 10 , 20, 30 and $40 \mathrm{~cm}$ showed light interception values of 56.15, 85.16, 93.39 and 96.57\%, respectively. It occurs and temporal variabilities on the $B$. decumbens pasture structure managed under continuous stocking.
\end{abstract}

Key Words: Brachiaria decumbens, bulk density of forage, forage mass, light interception, pasture height 


\section{Introdução}

A estrutura do pasto consiste na disposição espacial da biomassa aérea numa pastagem e pode ser caracterizada por variáveis como massa e densidade volumétrica de forragem, interceptação de luz pelo dossel e altura do pasto. Essa estrutura é relevante, porque condiciona as respostas deplantas e animais em regime depastejo(Carvalho etal., 2001).

A caracterização da estrutura do pasto é tarefa complexa, devido à sua variabilidade natural, causada pela desfolhação seletiva dos animais, e às condições de oferta de recursos tróficos no plano horizontal da pastagem, como fertilidade do solo e disponibilidade hídrica. Essa inerente variação espacial da vegetação na pastagem é denominada estrutura horizontal do pasto e tem sido pouco avaliada nos experimentos com animais em pastejo.

Além disso, a estrutura do pasto não é estática. É constantemente alterada por fatores que causam variações nas taxas de crescimento das plantas e/ou nos padrões de desfolhações. Essa dinâmica temporal modifica a estrutura horizontal do pasto ao longo do tempo, mesmo naqueles com uma única espécie e manejados com igual critério, como mesma altura média sob lotação contínua. Desse modo, é importante investigar essa dinâmica e não apenas caracterizar a estrutura média do pasto.

Assim, objetivou-se com este trabalho quantificar as características estruturais de Brachiaria decumbens cv. Basilisk em locais da mesma pastagem com diferentes alturas da forrageira.

\section{Material e Métodos}

O experimento foi conduzido de novembro de 2007 a maio de 2008 numa área de pastagem de Brachiaria decumbens cv. Basilisk (Stapf.) estabelecida em 1997, pertencente ao Setor de Forragicultura do Departamento de Zootecnia da Universidade Federal de Viçosa. A área experimental foi constituída de dois piquetes (unidades experimentais) de aproximadamente 0,30 ha cada, além de uma área reserva. O solo da área experimental é Latossolo
Vermelho-Amarelo de textura argilosa. A análise química do solo, realizada no início do período experimental, na camada 0 -20 cm, apresentou os seguintes resultados: $\mathrm{pH}$ em $\mathrm{H}_{2} \mathrm{O}$ : 5,1; P: 2,9 (Mehlich-1) e K: $85 \mathrm{mg} / \mathrm{dm}^{3} ; \mathrm{Ca}^{+2}: 2,05 ; \mathrm{Mg}^{2+}$ : $0,45 \mathrm{e} \mathrm{Al}^{3+}: 0,19 \mathrm{cmolc} / \mathrm{dm}^{3}(\mathrm{KCl} 1 \mathrm{~mol} / \mathrm{L})$. Durante o período de avaliação, os dados climáticos foram registrados em estação meteorológica distante da área experimental aproximadamente $500 \mathrm{~m}$ (Tabela 1 ).

A adubação fosfatada foi feita no dia 16 de janeiro de 2008 com a aplicação de $\mathrm{P}_{2} \mathrm{O}_{5}(70 \mathrm{~kg} / \mathrm{ha})$, na forma de superfosfato simples, em toda área experimental. A adubação nitrogenada, na forma de ureia, foi realizada em três aplicações de $50 \mathrm{~kg} / \mathrm{ha}$ de $\mathrm{N}$ ao final da tarde de cada data de aplicação (16/1/2008, 26/2/2008 e 7/4/2008).

Desde novembro de 2007, os piquetes foram manejados sob lotação contínua com taxa de lotação variável a fim de manter a altura do pasto em cerca de $25 \mathrm{~cm}$. Para isso, a altura do pasto foi monitorada duas vezes por semana e foram utilizados bovinos machos em recria com peso médio de $200 \mathrm{~kg}$.

Foram avaliadas quatro alturas de plantas $(10,20,30 \mathrm{e}$ $40 \mathrm{~cm}$ ) no mesmo pasto manejado com altura média de $25 \mathrm{~cm}$, em razão da natural variabilidade espacial da vegetação. Adotou-se o delineamento em blocos ao acaso com duas repetições.

No início de janeiro de 2008, o pasto de capim-braquiária foi infestado pela lagarta Mocis latipes, o que impediu a realização e continuidade das avaliações de campo iniciadas em meados de dezembro de 2007. Com a infestação da lagarta, retiraram-se os animais dos piquetes e fez-se aplicação do inseticida do grupo piretroide (Decis 25EC) na dose de $200 \mathrm{~mL} / \mathrm{ha}$. Os piquetes foram novamente utilizados sob pastejo, seguindo o mesmo manejo anterior, somente a partir de meados de fevereiro de 2008. Com exceção da variação da altura inicial do pasto, a avaliação das demais variáveis-respostas ocorreu na última semana de março.

Para determinação da variação da altura inicial do pasto, foram marcados seis pontos em cada área do pasto avaliada $(10,20,30$ e $40 \mathrm{~cm})$, totalizando 24 pontos por piquete. No dia da marcação, a altura das plantas foi medida nesses

Tabela 1 - Temperatura média diária, insolação, precipitação pluvial total mensal e evaporação total mensal no período de novembro de 2007 a maio de 2008

\begin{tabular}{lcccc}
\hline Mês & Temperatura média do ar $\left({ }^{\circ} \mathrm{C}\right)$ & Insolação (horas/dia) & Precipitação pluvial $(\mathrm{mm})$ & Evaporação $(\mathrm{mm})$ \\
\hline Novembro/2007 & 21,9 & 4,9 & 52,6 & 175,7 \\
Dezembro/2007 & 22,9 & 10,7 & 219,5 & 97,7 \\
Janeiro/2008 & 21,6 & 8,2 & 112,7 & 4 \\
Fevereiro/2008 & 22,7 & 8,5 & 239,2 & 67,1 \\
Março/2008 & 22,0 & 6,1 & 62,6 & 67,8 \\
Abril/2008 & 21,5 & 6,4 & 4,6 & 65,5 \\
Maio/2008 & 17,8 & 7,4 & & 66,2 \\
\hline
\end{tabular}


pontos utilizando-se régua graduada. Após cerca de 30 dias, que correspondeu ao ciclo de avaliação, foi mensurada novamente a altura das plantas nesses pontos. A variação na altura das plantas que inicialmente mediam 10, 20, 30 ou $40 \mathrm{~cm}$ foi calculada pela diferença entre a altura no primeiro e no último dia do ciclo de avaliação. Foram realizados dois ciclos de avaliação.

Para avaliação da massa de forragem, foram identificadas 12 áreas por piquete, com três áreas para cada altura (10, 20, 30 e $40 \mathrm{~cm}$ ). Nessas áreas, foram colhidos, rente ao solo, todos os perfilhos contidos no interior de um quadrado de $0,16 \mathrm{~m}^{2}$. Cada amostra foi acondicionada em saco plástico identificado e, no laboratório, foi pesada e subdividida em duas partes. Uma das subamostras foi pesada, acondicionada em saco de papel e colocada em estufa com ventilação forçada, a $65^{\circ} \mathrm{C}$, durante 72 horas, quando novamente foi pesada. A outra subamostra foi separada em lâmina foliar verde, colmo verde e material morto. A inflorescência e a bainha foliar verdes foram incorporadas à fração colmo verde. A parte da lâmina foliar que não apresentava sinais de senescência foi incorporada à fração lâminas foliares verdes. As partes do colmo e da lâmina foliar senescentes e mortas foram incorporadas à fração material morto. Após a separação, os componentes das plantas de capimbraquiária foram pesados e secos em estufa de circulação forçada a $65^{\circ} \mathrm{C}$, por 72 horas. O somatório das massas de lâminas foliares verdes e colmos verdes correspondeu à massa de forragem verde. A relação lâminas foliares verdes/ colmos verdes foi obtida pela divisão da massa de lâminas foliares verdes pela massa de colmos verdes.

A densidade volumétrica da forragem e de seus componentes morfológicos, expressa em $\mathrm{kg} / \mathrm{cm}$.ha, foi calculada pela divisão da massa de forragem e da massa de seus componentes morfológicos, respectivamente, pela altura das plantas no pasto em cada área.

Registrou-se também a interceptação luminosa pelo pasto de capim-braquiária com o analisador de dossel AccuPAR Linear PAR/LAI ceptometer, Model PAR -80 (DECAGON Devices). Em cada piquete e para cada área do pasto avaliada (10, 20, 30 e $40 \mathrm{~cm}$ ), foram escolhidas cinco locais para realização das leituras, na proporção de uma medida acima para cinco medidas abaixo do dossel. No total, foram tomadas 20 leituras acima do dossel e 100 leituras ao nível do solo por unidade experimental (piquete).

As análises dos dados experimentais foram feitas usando o Sistema para Análises Estatísticas - SAEG, versão 8.1 (UFV, 2003). Para cada característica, foi realizada a análise de variância e, posteriormente, análise de regressão, cujos modelos testados foram o linear e o quadrático. Também foram calculados os coeficientes de correlação linear entre a interceptação de luz pelo dossel e algumas características estruturais do pasto de capim-braquiária. Todas as análises estatísticas foram realizadas ao nível de significância de até $10 \%$ de probabilidade.

\section{Resultados e Discussão}

As médias de altura do pasto foram $23,6 \mathrm{~cm}$ no piquete 1 e $24,7 \mathrm{~cm}$ no piquete 2 (Tabela 2). Esses valores ficaram próximos da meta proposta inicialmente, que correspondeu à manutenção dos pastos com altura média de $25 \mathrm{~cm}$, o que indica que essa condição de manejo do pastejo foi estabelecida.

A variação na altura inicial do pasto apresentou resposta linear e negativa $(\mathrm{P}<0,10)$ com a altura das plantas nos locais da pastagem (Figura 1). Em locais do pasto com $10 \mathrm{~cm}$ de altura, no início das avaliações, ocorreu aumento de

Tabela 2 - Valores médios quinzenais das alturas do pasto de capim-braquiária no período de novembro de 2007 a maio de 2008

\begin{tabular}{|c|c|c|}
\hline \multirow[t]{2}{*}{ Quinzena/mês/ano } & \multicolumn{2}{|c|}{ Unidade experimental } \\
\hline & 1 & 2 \\
\hline $1^{\mathrm{a} / \text { novembro/2007 }}$ & 24,7 & 22,9 \\
\hline $2^{\mathrm{a}} /$ novembro/2007 & 24,9 & 26,1 \\
\hline 1\%/dezembro/2007 & 22,7 & 23,8 \\
\hline 2a/dezembro/2007 & 25,2 & 24,0 \\
\hline 1ªnaneiro/2008 & 22,4 & 27,1 \\
\hline 2a/janeiro/2008 & 22,9 & 22,3 \\
\hline $1^{\mathrm{a}} /$ fevereiro/2008 & 22,1 & 22,5 \\
\hline 2a/fevereiro/2008 & 22,8 & 24,9 \\
\hline $1^{\mathrm{a} / \mathrm{março/2008}}$ & 23,2 & 26,0 \\
\hline $2^{\mathrm{a}} / \mathrm{março} / 2008$ & 23,8 & 25,9 \\
\hline 1a/abril/2008 & 23,7 & 23,9 \\
\hline 2a/abril/2008 & 24,3 & 26,7 \\
\hline $1^{\mathrm{a}} / \mathrm{maio} / 2008$ & 23,6 & 24,9 \\
\hline $2^{\mathrm{a}} / \mathrm{maio} / 2008$ & 24,1 & 24,6 \\
\hline Média & 23,6 & 24,7 \\
\hline
\end{tabular}

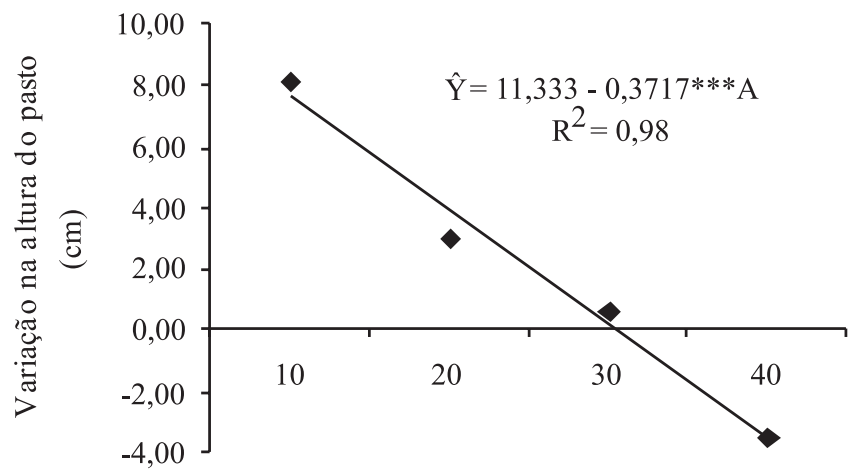

Altura da planta $(\mathrm{cm})$

***Significativo pelo teste $\mathrm{t}(\mathrm{P}<0,10)$.

Figura 1 - Variação da altura inicial em pasto de capim-braquiária determinada pela altura da planta (A). 
aproximadamente $8 \mathrm{~cm}$ no período de um mês. Mesmo padrão de resposta foi verificado para locais do pasto com altura inicial de $20 \mathrm{~cm}$, porém a magnitude desse acréscimo foi menor (cerca de $3 \mathrm{~cm}$ ). Por outro lado, nos locais com altura inicial de $30 \mathrm{~cm}$, praticamente não ocorreu variação de altura. Já nos locais originalmente com $40 \mathrm{~cm}$, ocorreu redução de $4 \mathrm{~cm}$ na altura das plantas.

É provável que dentro da amplitude de valores de altura avaliados nas áreas da pastagem e considerando as características morfológicas do capim-braquiária, os animais otimizaram o comportamento ingestivo pastejando em áreas com $40 \mathrm{~cm}$. De fato, pasto alto pode potencializar a profundidade do bocado animal e aumentar a massa do bocado, que é, frequentemente, a principal determinante da quantidade de alimento consumida por um animal em pastejo (Hodgson, 1990). Isso pode ter sido importante para o animal, uma vez que as avaliações ocorreram no final do verão e início do outono, época em que as condições climáticas tornam-se restritivas ao crescimento da planta e podem piorar sua estrutura pelo aumento da senescência.

Esses resultados indicam a instabilidade da estrutura do pasto de capim-braquiária, que se modifica ao longo do tempo, até quando o pasto é submetido ao mesmo tipo de manejo, como lotação contínua com taxa de lotação variável para manter altura média de $25 \mathrm{~cm}$. A modificação da estrutura vertical do pasto pode ser comprovada pela variação da altura das plantas em cada local do pasto avaliado. Já a alteração na estrutura horizontal pode ser constatada pela dinâmica das mudanças nos valores de altura das plantas nos pontos do mesmo pasto. A causa dessa dinâmica da estrutura do pasto pode ser atribuída às diferenças nas magnitudes das taxas de desfolhação pelo animal e de crescimento das plantas. Nesse sentido, todos os fatores que alteram os processos de desfolhação e crescimento interferem na dinâmica da estrutura do pasto. Esses fatores são numerosos, o que torna a compreensão dessa dinâmica bastante complexa.

As massas de lâmina foliar verde, colmo verde, material morto, forragem verde e forragem total aumentaram linearmente com a altura das plantas no pasto (Tabela 3).
As áreas do piquete com plantas de maior altura apresentaram maior $(\mathrm{P}<0,05)$ massa de forragem total (Tabela 3). Isso era esperado, já que a altura do pasto pode ser utilizada como medida indireta da massa de forragem em pastos de gramíneas tropicais, e a relação entre essas variáveis é, em geral, linear e positiva (Pedreira, 2002). De fato, Molan (2004) também verificou massas de forragem crescentes com a altura do pasto de capim-marandu manejado sob lotação contínua com bovinos. Em trabalho de Molan (2004), esse autor estudou quatro alturas médias do pasto $(10,20,30$ e $40 \mathrm{~cm})$, enquanto neste trabalho, avaliaram-se áreas com os mesmos valores de altura dentro de um único pasto manejado com altura média de $25 \mathrm{~cm}$. O aumento da massa de forragem total com a altura do pasto decorre da elevação, concomitante, das massas de todos os componentes morfológicos da forrageira que constituem a forragem total.

Nas áreas do pasto com plantas mais altas, os perfilhos são mais compridos e requerem colmo mais espesso e desenvolvido para sustentar seu maior peso. Além disso, nessas áreas do pasto, é possível que tenha ocorrido competição por luz entre os perfilhos e, como consequência, ocorreu o alongamento do colmo, como forma de expor as folhas mais jovens na parte superior do dossel, onde a luz é mais abundante (Da Silva \& Corsi, 2003). Esses argumentos justificam o aumento $(\mathrm{P}<0,10)$ da massa de colmos verdes nas áreas em que a forrageira era mais alta (Tabela 3).

$\mathrm{O}$ aumento da massa de colmo no pasto influencia a distribuição de folhas no perfil do dossel e modifica a quantidade e a qualidade da luz no seu interior, o que repercute diretamente nas características morfogênicas e no perfilhamento do pasto (Gomide et al., 2003). Com a elevação da massa de colmo, aumenta a produção de forragem, porém a estrutura do pasto é prejudicada pelo efeito negativo desse componente morfológico sobre o comportamento ingestivo do animal e a eficiência do pastejo (Carvalho et al., 2001).

A elevação $(\mathrm{P}<0,01)$ da massa de material morto nas áreas do pasto com plantas de maior altura (Tabela 3) pode ser justificada pela intensificação da competição por luz

Tabela 3 - Estimativas da massa de forragem e de seus componentes morfológicos conforme a altura (A) das plantas em pasto de capim-braquiária

\begin{tabular}{|c|c|c|c|c|c|c|}
\hline \multirow[t]{2}{*}{ Massa } & \multicolumn{4}{|c|}{ Altura da planta (cm) } & \multirow[t]{2}{*}{ Regressão } & \multirow[t]{2}{*}{$\mathrm{R}^{2}$} \\
\hline & 10 & 20 & 30 & 40 & & \\
\hline Lâmina foliar verde & 971 & 1.407 & 1.425 & 1.563 & $\hat{\mathrm{Y}}=893,752+17,9293 * \mathrm{~A}$ & 0,72 \\
\hline Colmo verde & 845 & 2.035 & 2.062 & 2.751 & $\hat{\mathrm{Y}}=487,366+57,4391 * * * A$ & 0,82 \\
\hline Material morto & 1.018 & 1.655 & 3.301 & 3.515 & $\hat{\mathrm{Y}}=88,0143+91,3660 * \mathrm{~A}$ & 0,89 \\
\hline Forragem verde & 1.816 & 3.444 & 3.487 & 4.314 & $\hat{\mathrm{Y}}=1.381,12+75,3684^{* *} \mathrm{~A}$ & 0,80 \\
\hline Forragem total & 2.834 & 5.099 & 6.789 & 7.829 & $\hat{\mathrm{Y}}=1.469,13+166,734 * * A$ & 0,96 \\
\hline
\end{tabular}

* Significativo pelo teste $\mathrm{t}(\mathrm{P}<0,01)$; ** Significativo pelo teste $\mathrm{t}(\mathrm{P}<0,05)$; *** Significativo pelo teste $\mathrm{t}(\mathrm{P}<0,10)$ 
entre as plantas nesse local do pasto. Dessa forma, o intenso sombreamento na parte inferior do dossel provavelmente resultou na maior senescência e/ou morte de perfilhos jovens e folhas mais velhas, que se encontram sobremodo nesse local do pasto. Isso contribuiu para o aumento da massa de material morto nas áreas com plantas mais altas na pastagem.

O aumento das massas de colmo verde e material morto com a altura das plantas (Tabela 3) ocorreu em locais do pasto em que a interceptação de luz pelo dossel esteve abaixo ou próxima de 95\% (Figura 3). Esse padrão de resposta não tem sido constatado em pastos tropicais manejados sob lotação intermitente e com altura correspondente à interceptação de 95\% da luz pelo dossel, condição em que a massa de lâmina foliar verde predomina no pasto (Da Silva \& Corsi, 2003). Contudo, o experimento foi desenvolvido sob lotação contínua, condição para a qual se tem relatado menor massa de material morto em pastos baixos (Faria, 2009), bem como semelhante percentual de colmo em pastos com distintas alturas médias (Molan, 2004).

Também foi verificado aumento crescente $(\mathrm{P}<0,01)$ da massa de lâminas foliares verdes com a altura das plantas dentro do pasto (Tabela 3). Em geral, pastos mais altos têm perfilhos com bainhas foliares de maior comprimento (Sbrissia, 2004). Nessa condição, a folha em expansão, especialmente aquela de nível intermediário de inserção no perfilho, percorre maior trajeto entre seu ponto de conexão com a região meristemática e a extremidade do pseudocolmo e, consequentemente, atinge maior tamanho. Desse modo, lâminas foliares mais compridas nas áreas de pasto mais alto podem explicar o aumento na sua massa de lâminas foliares verdes. Todavia, quando expressa em termos relativos, a massa de lâminas foliares verdes reduziu com a altura das plantas no pasto (de 34\% para 20\% para plantas com 10 e $40 \mathrm{~cm}$, respectivamente, dentro do mesmo pasto).

Como ocorreu aumento das massas de lâminas foliares verdes e colmos verdes, é natural que esse mesmo padrão de resposta tenha ocorrido com a massa de forragem verde (Tabela 3). Quando se comparam os coeficientes angulares das equações ajustadas para massas de lâminas foliares verdes, colmos verdes e material morto, nota-se que o maior valor ocorreu para a massa de material morto $(91,3660)$ e o menor, para a massa de lâminas foliares verdes (17,9293); já a massa de colmos verdes apresentou valor intermediário $(57,4391)$ (Tabela 3), comprovando que a altura do pasto tem efeito mais pronunciado sobre colmos verdes e material morto que sobre lâminas foliares verdes. Realmente, a maior ocorrência de senescência das lâminas foliares acaba compensando o maior comprimento da folha nos perfilhos em pastos altos, resultando em menor efeito da altura do pasto sobre a massa de lâminas foliares verdes.
Contrariamente ao ocorrido com as massas de forragem, houve redução linear $(\mathrm{P}<0,05)$ na relação lâmina foliar verde/ colmo verde com a altura das plantas no pasto (Figura 2). Embora tenha ocorrido elevação das massas de lâminas foliares verdes e colmos verdes (Tabela 3), o aumento da massa de colmos verdes foi muito mais acentuado, o que pode ser percebido pelo coeficiente angular da sua equação ajustada, que foi cerca de três vezes superior ao da equação ajustada para massa de lâminas foliares verdes. Com isso, a relação lâmina foliar verde/colmo verde diminuiu, o que pode comprometer o desempenho dos animais em pastejo, pois afeta negativamente a estrutura e o valor nutritivo do pasto.

Outras características estruturais do capim-braquiária também foram alteradas pela variação de altura no pasto, entre elas, a densidade volumétrica da forragem e de seus componentes morfológicos. A densidade volumétrica de lâmina foliar verde decresceu $(\mathrm{P}<0,05)$ com a altura das plantas no pasto. Mesma resposta foi observada $(\mathrm{P}<0,10)$ para as densidades volumétricas de forragem verde e forragem total. Por outro lado, não houve efeito $(\mathrm{P}>0,10) \mathrm{da}$ altura das plantas no pasto sobre as densidades volumétricas de colmo verde e material morto (Tabela 4).

A redução na densidade volumétrica de lâminas foliares verdes com o aumento da altura das plantas no pasto ocorreu pelo fato de o aumento da altura ter sido proporcional ao da massa de lâminas foliares verdes. Molan (2004), trabalhando com Brachiaria brizantha cv. Marandu, sob lotação contínua e em quatro alturas médias de pasto $(10,20,30$ e $40 \mathrm{~cm})$, também verificou que a densidade volumétrica de folhas foi tão maior quanto menor a altura média do pasto. Já a não-influência da variação das alturas nas densidades volumétricas de colmos verdes e

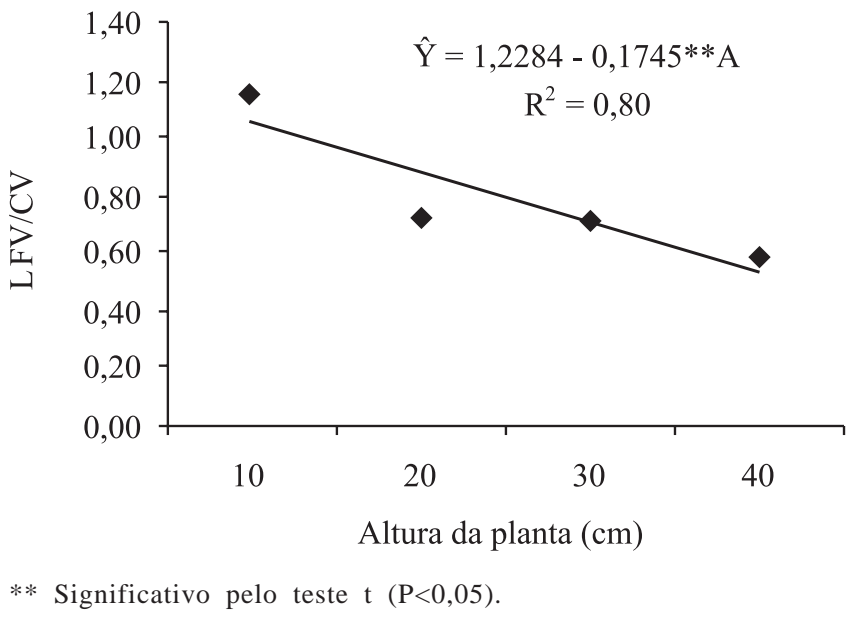

Figura 2 - Estimativa da relação lâmina foliar verde/colmo verde (LFV/CV) em quatro alturas (A) das plantas em pasto de capim-braquiária. 
material morto pode ser explicada em razão do aumento concomitante e de mesma magnitude da massa desses componentes morfológicos e da altura do pasto.

Como a densidade volumétrica de forragem verde consiste no somatório das densidades volumétricas de lâminas foliares verdes e colmos verdes, é coerente o seu decréscimo $(\mathrm{P}<0,10)$ com a altura das plantas no pasto, uma vez que a densidade volumétrica de lâminas foliares verdes reduziu e a densidade volumétrica de colmos verdes não foi afetada pela altura das plantas no pasto, conforme já descrito.

A densidade volumétrica de forragem total reduziu $(\mathrm{P}<0,10)$ com a elevação da altura das plantas no pasto. Esses resultados corroboram relatos de Molan (2004) de que a densidade volumétrica de forragem decresce com o aumento da altura média do pasto de capim-marandu sob lotação contínua.

Houve efeito quadrático $(\mathrm{P}<0,10)$ da altura do pasto sobre a interceptação de luz pelo dossel. Áreas da pastagem com alturas de 10, 20, 30 e 40 cm apresentaram interceptação luminosa correspondente a 56,2; 85,2; 93,4 e 96,6\%, respectivamente (Figura 3). Grasselli et al. (2000), em trabalho com $B$. decumbens em quatro alturas médias $(7,12,16$ e $22 \mathrm{~cm}$ ), também obtiveram padrão de resposta quadrático para a interceptação da radiação fotossinteticamente ativa, que elevou de acordo com as alturas do relvado, alcançando valor máximo de 90,5\% para altura do relvado de $20 \mathrm{~cm}$.

Somente as áreas do pasto com 30 e $40 \mathrm{~cm}$ apresentaram valores de interceptação de luz próximos a 95\%. Essa seria a condição de pasto em que ocorre a maior taxa de acúmulo de forragem (Parsons et al., 1988). Assim, de acordo com essa premissa, altura de pasto entre 30 e $40 \mathrm{~cm}$ permitiria que a máxima taxa de acúmulo de forragem fosse obtida com o capim-braquiária sob lotação contínua. Em verdade, o conceito de índice de área foliar crítico, condição na qual 95\% da luz incidente é interceptada pelo dossel, tem sido efetivo e válido para o manejo de gramíneas tropicais (Da Silva \& Nascimento Jr., 2006). Contudo, é necessário considerar que os dados obtidos neste experimento correspondem a um período de avaliação de dois meses, feito durante a transição do verão para o outono. Dessa maneira, para recomendações de manejo mais consistentes para a $B$. decumbens sob lotação contínua, devem ser realizados experimentos com maior duração, envolvendo todas as estações do ano, além de avaliações das respostas de plantas e animais aos distintos regimes de pastejo.

Uma das razões para a utilização do conceito de interceptação de luz para fins de recomendações de estratégias de manejos para as gramíneas tropicais baseia-se no fato de sua relação com algumas características estruturais do pasto, como altura e composição morfológica (Carnevalli et al., 2006). De fato, os valores de interceptação de luz pelo capim-braquiária correlacionaram-se negativamente com seu percentual de lâmina foliar verde $(\mathrm{P}<0,05)$, sua relação lâmina foliar verde/colmo verde $(\mathrm{P}<0,01)$ e sua densidade volumétrica de lâmina foliar verde $(\mathrm{P}<0,01)$. De outro modo, ocorreu associação positiva $(\mathrm{P}<0,05)$ entre interceptação de luz e massa de forragem no pasto de capim-braquiária (Figura 4).

Nas áreas da pastagem com plantas mais altas, portanto, onde ocorre maior interceptação de luz, ocorreram menores percentuais de lâminas foliares verdes, relação lâmina foliar

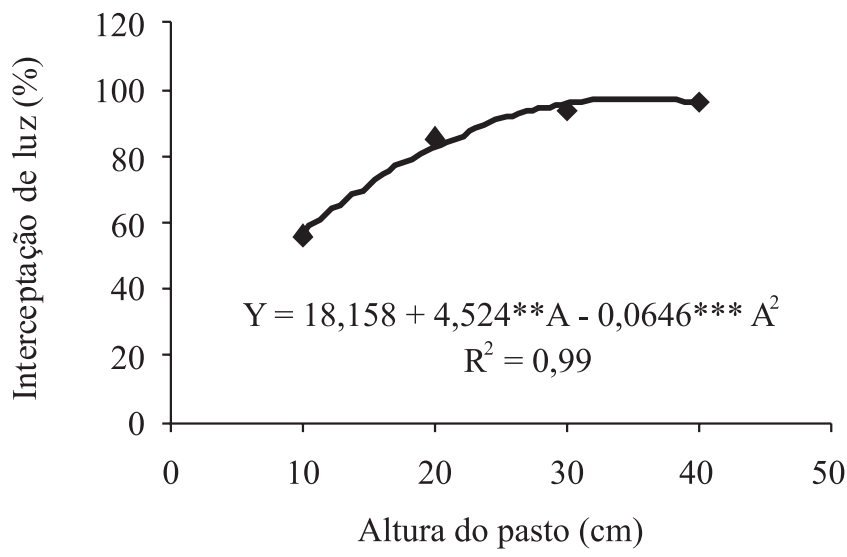

** Significativo pelo teste $\mathrm{t}(\mathrm{P}<0,05)$; ***Significativo pelo teste $\mathrm{t}(\mathrm{P}<0,10)$.

Figura 3 - Estimativa da interceptação de luz pelo dossel em pasto de capim-braquiária com alturas (A) das plantas.

Tabela 4 - Densidade volumétrica da forragem e de seus componentes morfológicos em pasto de capim-braquiária com quatro alturas (A) das plantas

\begin{tabular}{|c|c|c|c|c|c|c|}
\hline \multirow{2}{*}{$\begin{array}{l}\text { Densidade volumétrica } \\
\text { (kg/cm.ha de MS) }\end{array}$} & \multicolumn{4}{|c|}{ Altura da planta (cm) } & \multirow[t]{2}{*}{ Regressão } & \multirow[t]{2}{*}{$\mathrm{R}^{2}$} \\
\hline & 10 & 20 & 30 & 40 & & \\
\hline Lâmina foliar verde & 97,09 & 70,43 & 47,51 & 39,07 & $\hat{Y}=112,77-1,96968 * * A$ & 0,93 \\
\hline Colmo verde & 84,53 & 101,77 & 68,72 & 68,78 & $\bar{Y}=80,95$ & - \\
\hline Material morto & 101,78 & 82,76 & $\begin{array}{l}110,04 \\
116,23\end{array}$ & $\begin{array}{c}87,86 \\
107,85\end{array}$ & $\begin{array}{c}\bar{Y}=95,61 \\
\hat{\mathrm{Y}}=213,791-2,77261 * \mathrm{~A}\end{array}$ & $0, \overline{9} 0$ \\
\hline $\begin{array}{l}\text { Forragem verde } \\
\text { Forragem total }\end{array}$ & $\begin{array}{l}181,02 \\
283,39\end{array}$ & $\begin{array}{l}172,21 \\
254,96\end{array}$ & $\begin{array}{l}110,23 \\
226,27\end{array}$ & $\begin{array}{l}107,85 \\
195,72\end{array}$ & $\begin{array}{l}\hat{Y}=213,791-2,77261 * A \\
\hat{Y}=313,012-2,91707 * A\end{array}$ & 0,99 \\
\hline
\end{tabular}

** Significativo pelo teste $\mathrm{t}(\mathrm{P}<0,05)$; * Significativo pelo teste $\mathrm{t}(\mathrm{P}<0,10)$. 
verde/colmo verde e densidade de lâminas foliares verdes, assim, como maior massa de forragem, conforme descrito e explicado anteriormente. Esse padrão de resposta é o motivo da natureza dos coeficientes de correlação negativos dessas características com os valores de interceptação de luz pelo dossel de capim-braquiária (Figura 4).

A variação nos valores das características descritoras da condição do pasto de capim-braquiária em locais de mesma pastagem com plantas de diferentes alturas comprova a existência de variabilidade espacial da forrageira manejada sob lotação contínua. Essa assertiva é válida, pois as alturas foram avaliadas em um mesmo pasto manejado sob mesmo critério, ou seja, aproximadamente $25 \mathrm{~cm}$ de altura, o que caracteriza a diversidade de estruturas no plano horizontal da pastagem.

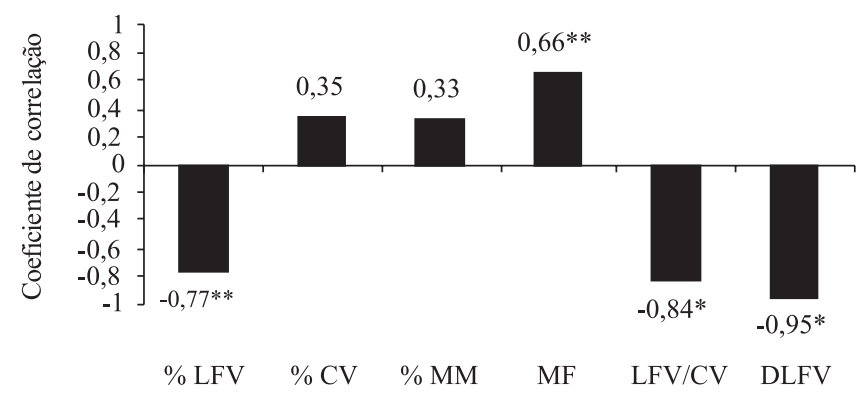

\% LFV - percentual de lâminas foliares verdes; \% CV - percentual de colmos verdes; \% MM - percentual de material morto; MF - massa de forragem (kg/ha); LFV/CV - relação entre as massas de LFV e CV; DLFV - densidade volumétrica de LFV.

*Significativo pelo teste $\mathrm{t}(\mathrm{P}<0,01)$; **Significativo pelo teste $\mathrm{t}$ $(\mathrm{P}<0,05)$.

Figura 4 - Coeficientes de correlação linear entre a interceptação de luz pelo dossel e as características estruturais do pasto de capim-braquiária sob lotação contínua.

\section{Conclusões}

Em um mesmo pasto de Brachiaria decumbens cv. Basilisk manejado sob lotação contínua com bovinos, ocorre variabilidade espacial e temporal das características descritoras da estrutura do dossel.

\section{Referências}

CARNEVALLI, R.A.; SILVA, S.C.; OLIVEIRA, A.A. et al. Herbage production and grazing losses in Panicum maximum cv. Mombaça pastures under four grazing managements. Tropical Grasslands, v.40, n.3, p.165-176, 2006.

CARVALHO, P.C.F.; RIBEIRO FILHO, H.M.N; POLI, C.H.E.C. et al. Importância da estrutura da pastagem na ingestão e seleção de dietas pelo animal em pastejo. In: REUNIÃO ANUAL DA SOCIEDADE BRASILEIRA DE ZOOTECNIA, 38., 2001, Piracicaba. Anais... Piracicaba: ESALQ, 2001. p.853-871.

DA SILVA, S.C.; CORSI, M. Manejo do pastejo. In: SIMPÓSIO SOBRE MANEJO DE PASTAGENS, 20., 2003, Piracicaba. Anais... Piracicaba: FEALQ, 2003. p.155-186.

DA SILVA, S.C.; NASCIMENTO JR., D. Ecofisiologia de plantas forrageiras. In: SIMPÓSIO SOBRE MANEJO ESTRATÉGICO DA PAStAGEM, 3., 2006, Viçosa, MG. Anais... Viçosa, MG: UFV, 2006. p.1-41.

FARIA, D.J.G. Características morfogênicas e estruturais dos pastos e desempenho de novilhos em capim-braquiária sob diferentes alturas. 2009. 145f. Tese (Doutorado em Zootecnia), Viçosa, MG.

GOMIDE, J.A.; CÂNDIDO, M.J.D.; ALEXANDRINO, E. As interfaces solo, planta e animal da exploração da pastagem. In: FORRAGICULTURA E PASTAGENS: TEMAS EM EVIDÊNCIA - SUSTEnTABilidAde, 4., 2003, Lavras. Anais... Lavras: Editora UFLA, 2003. p.75-116.

GRASSELLI, L.C.P.; GOMIDE, C.A.M.; PACIULLO, D.S.C. et al. Características morfogênicas e estruturais de um relvado de $B$. decumbens sob lotação contínua. In: REUNIÃO ANUAL DA SOCIEDADE BRASILEIRA DE ZOOTECNIA, 37., 2000, Viçosa, MG. Anais... Viçosa, MG: SBZ, 2000. (CD-ROM)

MOLAN, L.K. Estrutura do dossel, interceptação luminosa e acúmulo de forragem em pastos de capim-marandu submetidos a alturas de pastejo por meio de lotação contínua. 2004. 159f. Dissertação (Mestrado em Agronomia Ciência animal e Pastagens). Escola Superior de Agricultura Luiz de Queiroz, Piracicaba.

PARSONS, A.J.; JOHNSON, I.R.; WILLIAMS, J.H.H. Leaf age struture and canopy photosyntesis in rotationally and continuously grazed swards. Grass and Forage Science, v.43, n.1, p.1-14, 1988.

PEDREIRA, C.G.S. Avanços metodológicos na avaliação de pastagens. In: REUNIÃO ANUAL DA SOCIEDADE BRASIEIRA DE ZOOTECNIA, 39., 2002, Recife. Anais... Recife: Sociedade Brasileira de Zootecnia, 2002. p.100-150.

SBRISSIA, A.F. Morfogênese, dinâmica do perfilhamento e do acúmulo de forragem em pastos de capim-Marandu sob lotação contínua. 2004. 171f. Tese (Doutorado em Agronomia - Ciência Animal e Pastagens), Escola Superior de Agricultura "Luiz de Queiroz" (ESALQ), Piracicaba.

UNIVERSIDADE FEDERAL DE VIÇOSA - UFV. SAEG - Sistema de análises estatísticas e genéticas. Versão 8.1. Viçosa, MG: 2003. 57p. (Apostila). 